\title{
Professor Ajita Chakraborty
}

\author{
Dr Malay Kumar Ghosal \\ Professor, Dept of Psychiatry, Medical College, Kolkata
}

Professor Ajita Chakraborty was a rare breed of academicians who was also a good human being. These types of people are becoming less and less in number in the current society, and are an endangered species. Though it may sound flattering but it is true, I haven't seen any person more intelligent, reasonable and unfeigned.

Ajitadi, as being popularly called by her students and juniors (though sometimes we got a bashing for calling her didi, she used to tell that we could not come out of the dependency need!) passed away on $8^{\text {th }}$ of May 2015. She was born in preindependent India on $31^{\text {st }}$ October, 1926, in an era of social transitions and countrywide movement for independence. She went to study medicine and graduated from Medical College, Bengal. She went to England to get her higher studies and got her DPM and MRCP, FRCP. She came back to India after spending almost a decade in England. She was the first qualified female psychiatrist in India. She held many important academic posts and became the Head of the Department of Neurology and Psychiatry, and later became the director of Institute of Postgraduate Medical Education and Research, Kolkata. For being a Psychiatrist at the helm of affairs of Neurology, she had to face many adverse and unpleasant situations, but she handled them undauntedly. She served in many important posts of Indian Psychiatric Society (IPS). First she became the treasurer, then secretary and finally got elected as the president of IPS in 1976. She was the first lady president of IPS. She also received the lifetime achievement award conferred by Bombay Psychiatric Society.

Ajitadi was always a nonconformist and she was a very outspoken kind of person. For these reasons she was sometimes not liked by many people and often looked upon as a snob, which is an absolute mis- statement. She was a pioneer in the social and cultural psychiatry research, and has been admired and appreciated by the first line researchers of the world in cultural psychiatry like H B M Murphy, Raymond Prince, Lawrence Kirmayer, Ronald Littlewood, etc. She has served in the editorial board of Transcultural Psychiatry Research Review and later Transcultural Psychiatry for many years. She has published many articles in national and international journals for which The Lancet requested her to write an invited article on "Culture, Colonialism and Psychiatry" in 1991. She had very original thoughts in every article she wrote, and anyone who has gone through the article on "Moral values and Mental Health" (presidential address given in Nagpur) or the article on "Cargo cult in Calcutta - reappearance of a myth" published in 1971, will definitely conform to my view. Unfortunately Ajitadi never got the due recognition from Indian psychiatrists and many of the current students of psychiatry probably do not know her contributions. In Calcutta also, for some mysterious and mischievous reasons, she got post graduate trainee only at the fag end of her career. She got only four batches of students, and I am fortunate enough to be one of them. She had undertaken a huge survey in the metropolitan city of Calcutta, which also for some obscure reason was not accepted in Indian Journal of Psychiatry. The results were later published in a book "Social stress and mental health" by the Sage publications.

As a person she was always a perfectionist and everything in her office or in her house was kept very neatly. Being dressed most of the time in a properly ironed tant saree gave her a very graceful and elegant look. At the same time she was very receptive and open to discussions. Even if anyone didn't agree to her opinion she never took them personally and if can substantiated by proper reason 
would have accepted it. A personal anecdote will help to understand her. She had rejected my write up of review of literature for thesis four times. At the same time, she went to university to know the rules of late submission. Initially, we had a feeling of awe mixed with respect and tried to maintain a distance, but with passage of time we could get the essence of the inner self which was full of love and empathy. We had some discussions on the topic, "Is there anything called Indian self" and that was really very fascinating and interesting, though ultimately we could not reach a consensus. Several times we had group sessions with Ajitadi and those were very stimulating. She used to run a child guidance clinic in the Tiny Tot School after retirement and we used to go there and had some wonderful experience. She was an avid bird watcher and used to tell about how the birds were making nest in her roof, how the baby birds are hatched and so on. She wrote an autobiography in the later part of her life and I am quoting some lines from her book
"My professional life has led me along a lonely path, with little encouragement from other physicians... butmy persistence in evolving my own understanding and developing culturally appropriate treatment methods for my Indian patients has been infinitely rewarding!"

With the demise of Prof Ajita Chakraborty, an era has ended. I can still remember the warnings uttered by Prof Chakraborty in Bombay conference way back in 1983. She questioned how much and how far we should go for the sponsorships of Pharma companies. That was a visionary statement in that age. So in all respect we have lost an eminent academician, a prominent researcher and above all a great human being with impeccable integrity. She will be in our memory for her exemplary works.

May her soul rest in peace! 